\title{
Anesthetic experience in a clinically euthyroid patient with hyperthyroxinemia and suspected impairment of T4 to T3 conversion
}

- a case report-

\author{
Sang Hyun Lee, Jin Gu Kang, Moon Chol Hahm, Jeong Heon Park, Kyung-Mi Kim, Tae-Wan Lim, \\ and Young Ri Kim
}

Department of Anesthesiology and Pain Medicine, Dongtan Sacred Heart Hospital, Hallym University College of Medicine, Hwasung, Korea

We report an anesthetic experience in a clinically euthyroid patient with hyperthyroxinemia (elevated free thyroxine, fT4 and normal 3, 5, 3'-L-triiodothyronine, T3) and suspected impairment of conversion from T4 to T3. Despite marked hyperthyroxinemia, this patient's perioperative hemodynamic profile was suspected to be the result of hypothyroidism, in reference to the presence of T4 to T3 conversion disorder. We suspected that pretreatment with antithyroid medication before surgery, surgical stress and anesthesia may have contributed to the decreased T3 level after surgery. She was treated with liothyronine sodium (T3) after surgery which restored her hemodynamic profile to normal. Anesthesiologists may be aware of potential risk and caveats of inducing hypothyroidism in patients with euthyroid hyperthyroxinemia and T4 to T3 conversion impairment. (Korean J Anesthesiol 2014; 67: 144-147)

Key Words: Anesthesia, Euthyroid, Hyperthyroxinemia, Hyperthyroxinemia due to decreased peripheral conversion of T4.

Thorough evaluation of the thyroid function and achievement of the euthyroid state are critical in perioperative care because either hypo- or hyperthyroidism can result in catastrophic events and complications [1]. In the management of preoperative thyroid dysfunction, the patient should attain euthyroid status before the surgery and this should be confirmed with normalization of the serologic thyroid function tests, especially free thyroxine (fT4) [1,2].
However, in the case of euthyroid hyperthyroxinemia with suspected rare thyroxine (T4) to 3, 5, 3'-L-triiodothyronine (T3) conversion disorder, pretreatment with antithyroid hormone before surgery may be controversial. We report an anesthetic case in a patient with euthyroid hyperthyroxinemia and suspected $\mathrm{T} 4$ to $\mathrm{T} 3$ conversion disorder to whom pretreatment was given before surgery to prevent possible thyrotoxicosis.

Received: May 9, 2013. Revised: June 21, 2013. Accepted: July 23, 2013.

Corresponding author: Jin Gu Kang, M.D., Ph.D., Department of Anesthesiology and Pain Medicine, Dongtan Sacred Heart Hospital, Hallym University College of Medicine, 7, Keunjaebong-gil, Hwasung 445-170, Korea. Tel: 82-31-8086-2280, Fax: 82-31-8086-2029, E-mail: christopher@ hallym.or.kr

() This is an open-access article distributed under the terms of the Creative Commons Attribution Non-Commercial License (http:// creativecommons.org/licenses/by-nc/3.0/), which permits unrestricted non-commercial use, distribution, and reproduction in any medium, provided the original work is properly cited. 


\section{Case Report}

A 74-year-old woman (147 cm in height, weighing $37 \mathrm{~kg}$ ) was scheduled for a reoperation of left total hip replacement surgery. She had received several hip surgeries since 1981 because of a pedestrian traffic accident. She had a previous history of Hashimoto's thyroiditis, diagnosed in 2002. She had been on synthetic thyroxine medication, which was stopped in 2004 because of elevated f T4, and propranolol $40 \mathrm{mg}$ had been administered daily, but the patient was not on medication upon admission. She had not been on medications such as prophylthiouracil (PTU) or amiodarone.

Upon preoperative evaluation, thyroid function test (TFT) showed that thyroid stimulating hormone (TSH) was $6.02 \mu \mathrm{IU} / \mathrm{ml}$ (normal: $0.27-2.40 \mu \mathrm{IU} / \mathrm{ml}$ ), f T4 was > $7.77 \mathrm{ng} / \mathrm{dl}$ (normal: 0.93-1.70 ng/dl), and T3 was $93 \mathrm{ng} / \mathrm{dl}$ (normal: 80-200 ng/dl). Total T4 or free T3 level was not measured. The measured antithyroid antibodies were as follows: anti-thyroglobulin, antimicrosome, anti-TSH receptor and thyroid stimulating antibodies were $3094.2 \mathrm{U} / \mathrm{ml}$ (normal < $60 \mathrm{U} / \mathrm{ml}$ ), > $4000 \mathrm{U} / \mathrm{ml}$ (normal $<60 \mathrm{U} / \mathrm{ml}), 0.1 \mathrm{IU} / \mathrm{l}(<1.5 \mathrm{IU} / \mathrm{l})$ and negative, respectively. A huge goiter was observed on computed tomography (CT). Ultrasound examination showed a goiterous change with a diffuse heterogeneous parenchyma, and a thyroid scan showed no demonstrable cold or hot nodule. Surgery was delayed and she was referred to an endocrinologist for evaluation of the underlying causes of the abnormal TFT. On the primary evaluation, a brain magnetic resonance imaging scan (MRI) was obtained which revealed no evidence of a pituitary tumor. Thyrotropin-releasing hormone (TRH) stimulation was carried out which resulted in an exaggerated elevation of the TSH level (baseline TSH 7.76 to peak TSH 79.79). Thereafter, a TRH stimulation test was conducted with T3 suppression by administration of physiologic T3 medication, and the result was suppression of the TSH secretion. Therefore, the possibility of a TSH secreting pituitary tumor and resistance to thyroid hormone (RTH) was ruled out of her diagnosis, and inhibition of T4 to T3 conversion by 5 -deiodinase disorder was suspected. Her basal cortisol level was $9.9 \mu \mathrm{g} / \mathrm{dl}$ (normal: 7-21 $\mu \mathrm{g} / \mathrm{dl}$ ). Her basal adrenocorticotropic hormone (ACTH) level was $32.99 \mathrm{pg} / \mathrm{ml}$ (normal: 5-60 pg/ml). Thyroxine binding globulin (TBG) was $26.9 \mu \mathrm{g} / \mathrm{ml}$ (normal: 15.8-26.4 ug/ $\mathrm{ml}$ ) and albumin level was $3.3 \mathrm{~g} / \mathrm{dl}$ (normal: $3.2-5.2 \mathrm{~g} / \mathrm{dl}$ ).

In the meantime, she did not manifest symptoms of thyrotoxicosis such as palpitation, hypertension, diaphoresis or arrhythmia, and she was considered to be in a clinically euthyroid state despite a significant elevation of serum fT4 level. Cardiac evaluation showed an ejection fraction (EF) of $66 \%$ and mild diastolic dysfunction without regional wall motion abnormalities (RWMA) on echocardiography examination and a normal sinus rhythm on electrocardiogram. However, she was pretreated with methimazole $10 \mathrm{mg}$ for 15 days prior to surgery and Lugol's solution was also administered once for prophylaxis against perioperative thyroid storm. TFT results one day before surgery showed that the TSH was $5.55 \mu \mathrm{IU} / \mathrm{ml}$, f T4 was $>7.77 \mathrm{ng} / \mathrm{dl}$ and T3 was $78 \mathrm{ng} / \mathrm{dl}$.

Premedication was not given. On admission to the operating room, her blood pressure was 150/60 $\mathrm{mmHg}$, heart rate was 64 beats per minute (bpm). General anesthesia was induced with thiopental sodium $5 \mathrm{mg} / \mathrm{kg}$ and 8 vol\% sevoflurane mask ventilation. After administration of vecuronium $1 \mathrm{mg} / \mathrm{kg}$, despite the huge sized goiter, the trachea was easily intubated on the first attempt and anesthesia was maintained with desflurane 6 vol\% at 0.5 fraction of oxygen. The arterial blood pressure and central venous pressure were continuously monitored. She did not show signs of excess catecholamine stimulation, and on the contrary, she was hypotensive and bradycardiac throughout the surgery (systolic blood pressure $<90 \mathrm{mmHg}, \mathrm{HR}<50 \mathrm{bpm}$ ). After several injections of ephedrine 5-10 mg, norepinephrine was administered continuously at $0.1-0.15 \mu \mathrm{g} / \mathrm{kg} / \mathrm{min}$ during the surgery. Blood gas analyses were performed at regular intervals. Initial hemoglobin $(\mathrm{Hb})$ was $9.2 \mathrm{~g} / \mathrm{dl}$. Although the estimated blood loss was 800-1,000 ml, packed red blood cells were transfused 6 units to correct the preexisting dehydrated state and maintain the $\mathrm{Hb}$ level $>10 \mathrm{~g} / \mathrm{dl}$. $\mathrm{Hb}$ was $10.5 \mathrm{~g} / \mathrm{dl}$ in the immediate postoperative period. 2 units of fresh frozen plasma was administered. The intravenously administered fluids were crystalloid 1,300 ml, 5\% HES $500 \mathrm{ml}$ for the initial 30 minutes of surgery, and the total administered fluid was crystalloid $1,300 \mathrm{ml}$ and colloid $500 \mathrm{ml}$. Urinary output was maintained at $120 \mathrm{ml} / \mathrm{h}$ per hour. The esophageal temperature was measured throughout the surgery. The patient was heated with a warm blanket to maintain the temperature $>36.0^{\circ} \mathrm{C}$. At the end of surgery, she was weaned from norepinephrine, was successfully extubated and was transferred to the surgical intensive care unit (SICU).

Twelve hours after admission to the SICU, she became hypotensive, and dopamine was infused at $10 \mu \mathrm{g} / \mathrm{kg} / \mathrm{min}$. Her echocardiogram during the postoperative follow up showed an EF of $65 \%$ without RWMA. The input and output was balanced to maintain an euvolemic state. After elimination of putative causes for hypotension, postoperative TFT was performed on postoperative day (POD) 2, which showed TSH at $0.9 \mu \mathrm{IU} / \mathrm{ml}$, fT4 $>7.77 \mathrm{ng} / \mathrm{dl}$ and T3 $57 \mu \mathrm{g} / \mathrm{dl}$. Liothyronine sodium (T3) was orally administered at a starting dose of $10 \mathrm{ug} / \mathrm{d}$ and the dose was then elevated to $40 \mathrm{ug} / \mathrm{d}$. On POD 6, TFT result showed serum TSH 0. $91 \mu \mathrm{IU} / \mathrm{ml}$, free T4 $>7.77 \mathrm{ng} / \mathrm{dL}$ and T3 $161 \mathrm{ng} /$ dL. With the administration of T3, the blood pressure became elevated, but dopamine was tapered slowly until POD 6 after confirming TFT results of the elevated T3 level. She was transferred to the general ward on POD 6. On POD 15, she was taken off T3 medication because T3 became $254 \mathrm{ng} / \mathrm{dl}$ on the follow- 
Table 1. Perioperative Thyroid Function Test

\begin{tabular}{lcccccccc} 
& On admission & $\begin{array}{c}1 \text { day prior } \\
\text { to surgery }\end{array}$ & POD2 & POD6 & POD15 & POD27 & POD42 & POD70 \\
\hline TSH $\mu \mathrm{IU} / \mathrm{ml}$ & 6.02 & 5.55 & 0.9 & 0.91 & 0.14 & 11.89 & 14.48 & 0.34 \\
T3 ng/dl & 93 & 78 & 57 & 161 & 254 & 62 & 87 & 153 \\
$\mathrm{fT} 4 \mathrm{ng} / \mathrm{dl}$ & $>7.77$ & $>7.77$ & $>7.77$ & $>7.77$ & $>7.77$ & $>7.77$ & $>7.77$ & $>7.77$ \\
\hline
\end{tabular}

POD: postoperative days, TSH: thyroid stimulating hormone, fT4: free thyroxine, T3: 3, 5, 3'-L-triiodothyronine.

up tests, but the T3 medication was later resumed because T3 dropped to $62 \mathrm{ng} / \mathrm{dl}$ on POD 27. On POD 43, her serum TFT showed TSH of $14.48 \mu \mathrm{IU} / \mathrm{ml}$, free T4 $>7.77 \mathrm{ng} / \mathrm{dl}$ and T3 87 $\mathrm{ng} / \mathrm{dl}$, and she was discharged with a T3 of $20 \mu \mathrm{g} / \mathrm{d}$. Three weeks after discharge, she visited the endocrinology clinic, and the T3 was discontinued with a normalized T3 level (TSH $0.34 \mu \mathrm{IU} / \mathrm{ml}$, free T4 > 7. $77 \mathrm{ng} / \mathrm{dl}$ and T3 $153 \mathrm{ng} / \mathrm{dl}$ ). Perioperative TFT results are listed in Table 1.

\section{Discussion}

In this report, our patient, who had been previously diagnosed with Hashimoto's thyroiditis, was considered to be in a clinically euthyroid state despite hyperthyroxinemia, accompanied by $\mathrm{T} 4$ to $\mathrm{T} 3$ conversion impairment, on preanesthetic evaluation.

Euthyroid hyperthyroxinemia is known to elicit abnormally elevated serum total T4 or rarely fT4 concentrations, without evidence of clinical presentation of a thyroid abnormality [3]. Free T4 may be transiently or persistently elevated and may be associated with normal, low, or high T3 levels. By definition, patients with euthyroid hyperthyroxinemia do not have any clinical thyroid disease, therefore, treatment is not indicated in these patients [3].

Several disease entities may be suspected in clinically euthyroid patients with hyperthyroxinemia whose TFT shows elevated T4 and non-suppressed TSH [4]. Possible disorders are familial dysalbuminemic hyperthyroxinemia $(\mathrm{FDH})$, resistance to thyroid hormone (RTH) and conditions associated with decreased T4 to T3 conversion [5]. FDH presents elevated T4 with normal T3 and normal TSH (non-suppressible TSH). FDH can be confirmed by abnormal thyroid hormone binding proteins such as thyroxine-binding globulin (TBG), transthyretin and albumin, among which TBG has the highest affinity for thyroid hormones (T4 > T3) and carries about $80 \%$ of the bound hormones [5]. TRH shows increased fT3 and T4 with normal TSH (non-suppressible TSH) and normal thyroid hormone binding protein profiles [5]. Our patient's thyroid profile did not correlate with a diagnosis of FDH or RTH. Her TBG level was marginally at the upper limit of normal ranges. She had both elevated fT4 and TSH with normal T3, and TSH secretion was suppressed with TRH stimulation test after physiological T3 administration. The brain MRI findings showed no evidence of TSH-producing pituitary mass. Therefore, hyperthyroxinemia with decreased T3 was suspected to be associated with decreased T4 to T3 conversion.

T4 to T3 conversion may be decreased or impaired by fasting, systemic illness, acute trauma or medications such as propranolol, amiodarone, corticosteroid and PTU. Genetic mutations in type II deiodinase could also affect T4 to T3 conversion [6] because it has high affinity to T4 and converts T4 to T3. The patient had taken propranolol previously, but the drug was not administered after admission. Her basal cortisol and ACTH level were within normal ranges. Since our patient was an elderly female who had a previous history of Hashimoto's thyroiditis (chronic autoimmune thyroid disease) and had undergone several orthopedic hip surgeries, T4 to T3 conversion may have been impaired because of chronic systemic illness. However, she did not experience perioperative problems during the previous surgeries. On the other hand, she may have had unrecognized type II deiodinase deficiency, although the chances are extremely low.

The etiology of this patient's hyperthyroxinemia was not clearly determined, but she was clinically euthyroid with no symptoms of thyrotoxicosis. In the face of euthyroid hyperthyroxinemia and underlying chronic Hashmoto's thyroiditis, she was given prophylactic methimazole and Lugol's solution as pretreatment for the surgery to diminish the potential risk of thyrotoxicosis. However, she became hypothyroid after surgery, and on retrospective speculation after the surgery, she was suspected to have been in subclinical hypothyroidism because of the coexisting Hashmoto's thyroiditis and T4 to T3 conversion impairment despite the preoperative hyperthyroxinemia. She could have become hypothyroid after the surgery, partly owing to the antithyroid pretreatment and surgical stress. Regarding her thyroid disease entity, she may have been suspected of hypothyroidism and tested for it immediately after surgery, but TFT was performed on POD 2 because the ICU clinician tried to rule out more common etiologies for hypotension such as a cardiac problem and volume status related problem. T3 was administered to correct the low serum T3 level on POD 2. Had the clinicians been more cautious about her thyroid disease, 
the possibility of hypothyroidism could have been anticipated and tested for earlier. In the meantime, it is precarious to draw conclusions on whether hypothyroidism was the major reason for hypotension during the surgery because the TFT was carried out only on POD 2. Because T3 is more potent and less protein bound than T4, and most T3 is formed peripherally from partial deiodination of T4, antithyroid pretreatment may render the patient with T3 to T4 conversion impairment, at an increased risk of hypothyroidism [6]. Anesthesia could also transiently decrease T4 to T3 conversion, and the decrease in the T3 level may be sustained up to 24 hours postoperatively [6]. Surgical stress can also incite hypothyroidism [6].

In conclusion, in a clinically euthyroid patient with hyperthyroxinemia, it may be kept in mind that antithyroid pretreatment, several medications, anesthesia and surgery can further hamper T4 to T3 conversion, and cause hypothyroidism despite a high free T4 level, especially if the patient has a preexisting underlying thyroid disease such as Hashimoto's thyroiditis and suspected impaired T4 conversion to T3. Anesthesiologists may be aware of the potential risks and caveats of inducing hypothyroidism during the perioperative care in such patients.

\section{References}

1. Kohl BA, Schwartz S. How to manage perioperative endocrine insufficiency. Anesthesiol Clin 2010; 28: 139-55.

2. Bartalena L, Bogazzi F, Brogioni S, Burelli A, Scarcello G, Martino E. Measurement of serum free thyroid hormone concentrations: an essential tool for the diagnosis of thyroid dysfunction. Horm Res 1996; 45: 142-7.

3. Borst GC, Eil C, Burman KD. Euthyroid hyperthyroxinemia. Ann Intern Med 1983; 98: 366-78.

4. Uy HL, Reasner CA 2nd. Elevated thyroxine levels in a euthyroid patient. A search for the cause of euthyroid hyperthyroxinemia. Postgrad Med 1994; 96: 195-202.

5. Alegre M, Meléndez EG, Colón G. Etiology and outcome of non-estrogen associated hyperthyroxinemia in euthyroid patients at the San Juan City Hospital. Bol Asoc Med P R 1996; 88: 12-5.

6. Jameson JL, Weetman AP. Disorders of the thyroid gland. In: Harrison's principles of internal medicine. 15th ed. Edited by Braunwald E, Hauser SL, Fauci AS, Longo DL, Kasper DL, Jameson JL: New York, The McGraw-Hill Companies, Inc. 2001, pp 2062-6. 